\title{
Remediation of arsenic-contaminated soils and washing effluents
}

\author{
Min Jang , Jung Sung Hwang , Sang II Choi , Jae Kwang Park
}

Introduction

Arsenic and other heavy-metal contaminations into

water and soil systems are creating potentially serious

environmental problems for humans and other living

organisms. Mining wastes and acid mine drainages have

released several heavy metals (arsenic, cadmium, copper,

lead, mercury, chromium, etc.) to ground- and surfacewater

systems as well as geological environments due

to their solubility and mobility (Mulligan et al., 2001).

Heavy-metal or toxic metalloid releases from about

894 among 900 of abandoned metal mines are raising

significant environmental problems in Korea. Although

the released arsenic can be immobilized in tailings or

soil, it can be easily spread into other regions through the transport of arsenic-contaminated solids and arsenic dissolution occurred by changes in the geo-chemical environment to a reductive condition. Therefore, before

arsenic reaches a waterbody or groundwater, arseniccontaminated

soils must be treated. There are several

technologies of reducing arsenic contamination or

mobility. Mulligan et al. (2001) evaluated remediation

technologies of heavy-metal contaminated soils

and groundwater such as isolation and containment, mechanical and pyrometallurgical separation, chemical treatment, permeable treatment walls, electrokinetics, biochemical processes, phytoremediation, in situ soil flushing, and soil washing. Among remediation technologies, soil washing can physico-chemically extracts heavy-metals or metalloids adsorbed onto soils and reduce the volume of arsenic-contaminated soils. In addition, soil washing can be applied to large contaminated areas due to its rapid kinetics, operational easiness, and economical efficiency (USEPA, 2001). Several types of extractants can be used to extract heavy-metals from tailings or soil for soil washing technology. The application 
of inorganic salts (potassium phosphate, potassium chloride, potassium nitrate, potassium sulfate, or sodium perchlorate) (Alam et al., 2001), inorganic acids (sulfuric acid, nitric acid, phosphoric acid, hydrochloric acid, or mixed acid) (Tokunaga and Hakuta, 2002), organic acids (citric or acetic acids) (USEPA, 2002), and alkaline agents (e.g., sodium hydroxide) (Legiec et al., 1997; Jackson and Miller, 2000) have so far been studied. Alam et al. (2001) tried to apply several salts for arsenic extraction from a model soil and found that potassium phosphate was most effective in extracting arsenic with more than $40 \%$ extraction in the $\mathrm{pH}$ range of 6-8. Tokunaga and Hakuta (2002) studied acid washing by artificially contaminating Kuroboku soil with arsenic and washing with different concentrations of several acids or mixed acids. Phosphoric acid was found to be most effective in a wide range of concentrations. However, it was not possible to extract and remove selectively a target heavy metal since inorganic acids under $\mathrm{pH}<2$ extract heavy metals simultaneously from soil due to ionization effects at low $\mathrm{pH}$ conditions. Unlike inorganic acids, alkaline agents can selectively extract arsenic from solids into the liquid phase through ion exchange since hydroxyl ions have an affinity higher than other anionic species such as arsenic, phosphorus, or selenium (Johnston and Heijnen, 2001). Legiec et al. (1997) applied alkaline leaching to remove arsenic from contaminated soils in their soil washing technique. Although Legiec et al. found that sodium hydroxide could specifically extract arsenic with higher efficiencies than other reagents such as monoammonium phosphate, hydrochloric acid, and $\mathrm{Na}_{2} \mathrm{CO}_{3}$, the results were not properly explained. Furthermore, there were no studies on the optimization of the extraction process and treatment of alkaline washing effluents.

Thus, in this study, the following objectives were established to investigate the applicability of alkaline washing for arsenic contaminated tailings or soil remediation. The specific objectives are as follows: (1) determine the physico-chemical properties and arsenic partitioning into different compartments of tailings or soil through sequential extraction, (2) evaluate the kinetics 
of arsenic extraction with different types of extractants

for arsenic-contaminated tailings or soil, (3) find

the relationship between arsenic partitioning characteristics

and arsenic extraction efficiencies, and (4) determine

the removal efficiency of arsenic in washing

solutions by $\mathrm{pH}$ adjustment or ferric chloride addition.

Materials and methods

Soil selection and characteristics

Samples were collected from arsenic-contaminated

areas in which arsenic levels were over 15 mgkg_1, corresponding

to the concern level of the Soil Environment

Conservation Act of Korea (MOE, 2003). As an original

arsenic source and representative of high-level arsenic

contamination, arsenic-contaminated tailings were collected

from the Nakdong mine (Jungsun, Kangwondo,

South Korea), which had been developed as an arsenic

mine. As the secondary contaminated areas and representative

of middle- and low-level arsenic contamination,

two different soil samples were collected from a

field and the other from river sediments located near

the Suksan mine located in Gunwi (Kungsanbookdo,

South Korea). Similar to the Nakdong mine, arsenic

concentrations of tailings in the Suksan mine have also

been known to have high and variable arsenic concentrations

of 81-558 mgkg_1 measured by the Korean

Standard Test (KST) method (MOE, 2002). These soil

samples were sieved through a $0.83-\mathrm{mm}$ opening sieve

(\#20) to remove large particles and provide a homogeneous

soil size. Characteristics of each sample such as

$\mathrm{pH}$, particle density, effective size (D10), uniformity coefficient

( $\left.\mathrm{D}_{60} / \mathrm{D}_{10}\right)$, and organic content were measured by

Methods of Soil Analysis (Page et al., 1986). Measurement

of cation exchange capacity (CEC) was conducted

by EPA Method 9080 (USEPA, 1986b). The total arsenic

concentration of soil samples was measured by

EPA 3050B (USEPA, 1986a) that is a hot nitric acid 
digestion method for soil. After pulverizing dried soil samples homogeneously, about $1 \mathrm{~g}$ was inserted into a glass beaker and $10 \mathrm{ml}$ of nitric solution (50\%) was added. The beaker was covered with a watch glass and heated to about $95 \pm 5 \_\mathrm{C}$ and refluxed for $15 \mathrm{~min}$. After cooling the sample, the concentrated nitric acid was repeatedly added and evaporated to $5 \mathrm{ml}$, then, cooled again. Then, hydrogen peroxide (30\%) was repeatedly added and $10 \mathrm{ml}$ of concentrated hydrochloric acid was added, then, refluxed again for $15 \mathrm{~min}$. The sample was filtered with Watman No. 41 and diluted to $100 \mathrm{ml}$ at volumetric flask, and analyzed for arsenic concentration.

As a disposal or reuse criterion of arsenic-contaminated tailings or soil samples, the KST methods for soils were adopted from the Soil Environment Preservation Act (MOE, 2003) to extract arsenic, cadmium, and lead. The strictest regulation (6 $\mathrm{mgkg}_{-}$of arsenic) for the KST methods was selected as a strategy of soil remediation, while toxicity characteristics leaching procedure (TCLP) tests were conducted to determine the suitability of landfilling treated soils in municipal landfills. The KST method is as follows: (1) add $50 \mathrm{ml}$ of hydrochloric acid (1 M) to each $10 \mathrm{~g}$ of soil sample, (2) shake the suspension at a speed of 100 rpm and $30 \_$C for $30 \mathrm{~min}$, (3) centrifuge $10 \mathrm{ml}$ of suspension at $3200 \mathrm{rpm}$ for $20 \mathrm{~min}$, and (4) filter the supernatant with a 0.6-1m micropore filter, dilute the filtrate, and acidify the filtrate with $\mathrm{HNO}_{3}$ until the concentration of $\mathrm{HNO}_{3}$ reaches $1 \%$ before the arsenic analysis. The TCLP test was conducted by the method suggested by EPA (USEPA, 1992). Arsenic, lead, and cadmium concentrations of filtrates were measured using inductively coupled plasma spectrometry (ICP-1000VI, Shimadzu Company, Japan) under the concentration range of $0.02-20$ mgl_1. For the arsenic precipitation tests, concentrations of metal species such as iron, silicon, aluminum, and manganese were determined by ICP while arsenic were measured by atomic absorption spectroscopy (AA-6401F, Shimadzu _, Japan) connected with a continuous hydride generator (HVG-1, Shimadzu_, Japan) that has a detection limit of $0.5 \mathrm{lgl}$ 1. Duplicates, blank and EPA reference standards were analyzed with each set of samples as a quality control check on the analysis. 
Arsenic sequential extraction procedure

In order to obtain the information of chemical speciation

and bonding strength of arsenic species, the

sequential extraction analysis procedure employed by

Kim et al. (2003) was adopted. Although sequential

extractions are operationally defined and not fully specific

in extracting the element bound to a given fraction,

it can provide comparative information to elucidate the

relative contribution of target compound and aid in the

predictions of elemental mobility (Keon et al., 2001;

Pueyo et al., 2003). According to the target binding

phases, apportions of arsenic in mgkg_1 can be quantified

with high sensitivity (Keon et al., 2001). The detailed

sequential extraction is as follows: (1) add $25 \mathrm{ml}$

of $0.25 \mathrm{M} \mathrm{KCl}$ to $2.5 \mathrm{~g}$ of sample in a $250-\mathrm{ml}$ volumetric

flask to extract the soluble fraction of arsenic species and

stir the slurry for $2 \mathrm{~h}$; (2) extract the adsorbed fraction of

arsenic species by adding $0.1 \mathrm{M} \mathrm{Na}_{2} \mathrm{HPO}_{4}(25 \mathrm{ml}, \mathrm{pH}$

8.0) and stirring for $20 \mathrm{~h}$; (3) extract the carbonate fraction

by adding $1 \mathrm{M}$ sodium acetate $(25 \mathrm{ml})$ and stirring

for $5 \mathrm{~h}$, and add $0.1 \mathrm{M} \mathrm{Na}_{2} \mathrm{HPO}_{4}(25 \mathrm{ml})$ and stir for 20

$\mathrm{h}$; (4) extract the soil organic matter fraction by adding

$5 \% \mathrm{NaOCl}(10 \mathrm{ml})$ at $\mathrm{pH} 9.5$ and heating at $70 \pm 0.5 \_\mathrm{C}$

for $30 \mathrm{~min}$ and repeat this step once; (5) extract the easily

reducible oxide fraction by adding $0.1 \mathrm{MNH}_{2} \mathrm{OH}(25$

$\mathrm{ml})$ at $\mathrm{pH} 2$ and stirring for $30 \mathrm{~min}$, add $0.1 \mathrm{M} \mathrm{KOH} \mathrm{(25}$

$\mathrm{ml}$ ), and stir for $20 \mathrm{~h}$; (6) extract the amorphous oxide

fraction by adding $0.25 \mathrm{MNH}_{2} \mathrm{OH} / \mathrm{HCl}(25 \mathrm{ml})$ and stirring

for $30 \mathrm{~min}$ at $50 \pm 0.5 \_\mathrm{C}$, add $0.1 \mathrm{M} \mathrm{KOH}(25 \mathrm{ml})$,

and stir for $20 \mathrm{~h}$; and (7) extract the operationally

defined crystalline mineral fraction of crystalline oxide

and amorphous aluminosilicates by adding aqua regia

(30 $\mathrm{ml} \mathrm{HCl}$ and $10 \mathrm{ml} \mathrm{HNO}_{3}$ ) and stirring for $1 \mathrm{~h}$. The

stirring condition of the above arsenic sequential

extraction procedures was $120 \mathrm{rpm}$. An aliquot of 10

$\mathrm{ml}$ of supernatant was taken and centrifuged at 3200

rpm for $20 \mathrm{~min}$, and then filtered with a $0.45-1 \mathrm{~m}$ micropore

filter.

Kinetics of soil washing

Hydrochloric acid and citric acid that have been reported 
to be effective for extracting heavy-metals in other studies (Benschoten et al., 1994; Cheong et al., 1997). These acids were selected to compare the effectiveness of arsenic extraction of contaminated tailings and soil with sodium hydroxide. Aliquots of $50 \mathrm{mM}$ and $100 \mathrm{mM}$ of each reagent were used for kinetic studies of arsenic extraction. Fifteen grams of each soil sample were carefully put in a $500 \mathrm{ml}$ flask and then $300 \mathrm{ml}$ of reagent solution was slowly added to achieve a ratio of reagent solutions $(\mathrm{ml})$ to soil mass $(\mathrm{g})$ of 20 . The suspension was mixed at $20 \pm 0.5 \_\mathrm{C}$ in a shaker at $300 \mathrm{rpm}$. At predetermined times $(1,2,3,6,14$, and $24 \mathrm{~h}), 10 \mathrm{ml}$ of supernatant was centrifuged at $3200 \mathrm{rpm}$ for $20 \mathrm{~min}$ and filtered with a $0.45-1 m$ filter paper. In order to examine the arsenic extraction mechanism, kinetic data were fitted with four mathematical models: first-order, parabolic diffusion, Elovich, and power function.

Through comparing the determination coefficients and standard errors of each model, the best fit model was found.

\section{Full text is available at :}

http://www.sciencedirect.com/science/article/pii/S0045653505000251 